\title{
GROUNDWORK
}

\section{High-stakes Collaborative Testing: Why Not?}

Ruth E. Levine a, Nicole J. Borges ${ }^{\text {b }}$, Brenda J.B. Roman ${ }^{\text {c }}$, Lisa R. Carchedi d, Mark H. Townsend ${ }^{e}$, Jeffrey S. Cluver ${ }^{f}$, Julia Frank ${ }^{g}$, Oma Morey ${ }^{h}$, Paul Haidet ' and Britta M. Thompson ${ }^{\mathrm{i}}$

a Office of Clinical Education and Department of Psychiatry and Behavioral Sciences, The University of Texas Medical Branch, Galveston, Texas, USA, ${ }^{b}$ Office of Academic Affairs, Wright State University Boonshoft School of Medicine, Dayton, OH. Dr. Borges is now at the University of Mississippi Medical Center, Jackson, Mississippi, USA;: ${ }^{\circ}$ Office of Curriculum and Department of Psychiatry, Wright State University, Boonshoft School of Medicine, Dayton, Ohio, USA; d Department of Psychiatry, University of Texas Southwestern Medical Center, Austin, Texas, USA; eDepartment of Psychiatry, Louisiana State University Health Sciences Center, New Orleans, Louisianna, USA; ${ }^{\dagger}$ Department of Psychiatry and Behavioral Sciences, Medical University of South Carolina, Charleston, South Carolina, USA; g Department of Psychiatry, George Washington University School of Medicine, Washington, DC, USA: ${ }^{h}$ Office of Educational Development, University of Texas Medical Branch, Galveston, Texas, USA; i Woodward Center for Excellence in Health Sciences Education, Pennsylvania State University College of Medicine, Hershey, Pennsylvania, USA.

Key words: academic performance, emotional intelligence, Team-Based Learning; teamwork; collaborative testing

Contact: Ruth E. Levine MD, The University of Texas Medical Branch, 301 University Blvd, Graves 2.210, Galveston, Texas 77555-0413 Phone: 409-7470269, Fax: 409-772-6565, email: rlevine@utmb.edu twitter:@rlevinetx and @OED_UTMB

Utmb.edu/oce 


\begin{abstract}
Phenomenon:

Studies of high-stakes collaborative testing remain sparse, especially in medical education. We explored high-stakes collaborative testing in medical education, looking specifically at the experiences of students in established and newly formed teams. Approach:

Third year Psychiatry students at 5 medical schools across 6 different sites participated, with 4 participating as established team sites and 2 as comparison team sites. For the collaborative test, we used the National Board of Medical Examiners (NBME) Psychiatry subject test, administering it via a two-stage process. Students at all sites were randomly selected to participate in a focus group, with 8-10 students per site $(\mathrm{N}=49)$. We also examined quantitative data for additional triangulation.
\end{abstract}

\title{
Findings:
}

Students described a range of heightened emotions around the collaborative test yet perceived it as valuable regardless if they were in established or newly formed teams. Students described learning about the subect matter, themselves, others, and interpersonal dynamics during collaborative testing. Triangulation of these results via quantitative data supported these themes.

Insights:

Despite student concerns, high-stakes collaborative tests may be both valuable and feasible. The data suggests that high-stakes tests (tests of learning or summative evaluation) could ALSO become tests for learning or formative evaluation. The paucity of research into this methodology in medical education suggests more research is needed. 


\section{Phenomenon}

Collaborative testing is a learning strategy in which students work together to complete a test as a group. It has been used in $\mathrm{K}-12$, as well as nursing and college-level physics education. ${ }^{1-4}$ Studies of collaborative testing within the classroom setting suggest that it can improve academic performance, critical thinking, communication, and teamwork skills while decreasing test anxiety. ${ }^{1-4}$ Studies in nursing education and exercise physiology show that collaborative testing improves retention of content. ${ }^{5-6}$ Other publications ${ }^{7}$ suggest that collaborative testing can result in increased retention of concepts that were originally missed by a student. Interestingly, high-stakes collaborative testing remains rare across all types of educational settings. ${ }^{2}$ For the purpose of this report, "high stakes" collaborative testing is defined as collaborative testing that occurs during summative assessment or testing which has significant bearing on a learner's performance assessment.

Many variations of collaborative testing exist, such as the one-stage testing (students only take a team test) versus the two stage testing model (students take a test first as an individual and then as a team), use of a consensus answer (each team submits one consensus test) versus each member submitting their own collaborative test, and use of randomly assigned team members versus self-selected members. All of these variations can influence the outcomes of collaborative testing, along with other factors such as the quality and complexity of test questions and whether the results of the collaborative test are factored into a student's final grade (or not). A recent review had called for more research regarding collaborative testing, especially studies that include comparison or control groups and ones that differ in only a few variables. ${ }^{1}$ 
Studies of high-stakes collaborative testing remains sparse, especially in medical education. In particular, there is a paucity of research regarding the influence of previous team experience on high-stakes collaborative testing. Our study sought to describe, using qualitative methods, high-stakes collaborative testing in medical education, looking specifically at the experiences of established teams (those that had worked as a team in a Team-Based Learning curriculum prior to the collaborative test) as well as those of newly formed teams (students who had not worked as a team in a clerkship that used conventional didactics prior to the collaborative test). Because we used qualitative methodology, our purpose was to understand the experiences of students, not to quantitatively compare the two types of teams.

\section{Approach}

Participants

Third year Psychiatry students at 5 different medical schools across 6 different sites participated in this study. Four sites participated as established teams via Teambased learning (TBL) (The University of Texas Medical Branch (UTMB), Galveston, UTMB, Austin, Louisiana State Health Science Center New Orleans, and Wright State University Boonshoft School of Medicine) and two participated as "usual educational practice" with newly formed teams at comparison sites (George Washington School of Medicine and Health Sciences, The Medical University of South Carolina) during the 2012-13 academic year. Institutional review board approval for the study was obtained at each school, respectively. Table 1 provides information regarding the characteristics of students at each of the schools. For established teams, 5-7 students were formed at each site based on best practices in TBL and number of students in each clerkship rotation. ${ }^{8}$ 
All of the established team schools employed the essential elements of TBL ${ }^{8-10}$ including instructor formed teams, individual and then group readiness assurance quizzes utilizing immediate feedback, and higher order application exercises wherby teams debated and simultaneously revealed specific choices to challenging clinical questions. Over the course of the Psychiatry clerkship, students in established teams participated in at least four and up to nine TBL team sessions while comparison teams did not formally meet within their teams until the collaborative test.

For our collaborative test, we used a nationally-created test, the National Board of Medical Examiners (NBME) Psychiatry Subject test, and administered it via a two-stage testing process. We imposed the same testing conditions on established and comparison teams. Students in both the established and newly formed comparison teams first took the test individually. After submitting their individual test answer sheets, students took a 30minute break while remaining in the proctored environment where they could not discuss the test. Following the break, the students took the same test in teams; with all members working together to collectively complete a single consensus test. Results from the collaborative test factored into students' final grade, though it was a relatively modest percentage of the overall grade (e.g. 5\%). Despite the fact the percentage of the grade was modest it was large enough that students perceived the test as a significant summative assessment, hence our belief that this was a high-stakes collaborative test. Performance on the test could make the difference in some cases between a "High Pass" or an "Honors" grade, so students clearly experienced the test as a high stakes exercise.

\section{Data Collection and Analysis}


Students in established and newly formed comparison teams were randomly selected to participate in a focus group regarding their experience participating in the collaborative test, with 8-10 students at each site $(\mathrm{N}=49)$. Before each focus group students provided informed consent. Students received a meal and a $\$ 30$ gift card to compensate for their time and effort.

We created a semi-structured focus group guide through a pilot study of evaluation questions posed to students not involved in the focus group as well as consensus of three educational researchers involved in the project. We were interested in their experiences of participating in a high-stakes collaborative test. Example questions in the guide included, "How did you feel about the team test, about having the team test influence your grade?" and "Describe your experience of taking the team test." A complete copy of the guide is included in table 2 . One of three educational researchers (NJB, OM, PH) experienced in conducting focus groups facilitated. Focus groups lasted approximately 60 minutes and were audio recorded and then transcribed.

Focus groups yielded 192 double-spaced pages of text. We used a narrative analysis using a thematic framework for data coding, therefore, the unit of analysis was each unique story. This framework allowed us to analyze the unique experience of participants. The team of analysts included a psychiatrist (REL), an educational psychologist (BMT) and a clinical psychologist (NJB), all who were medical educators experienced in qualitative data analysis. Two analysts (NJB and REL) read each individual transcript multiple times and coded for themes and categories. These analysts engaged in an iterative process of individual reading and coding followed by two sessions of discussion and consensus of the categories and themes. 
We ensured triangulation of our data, or the use of multiple methods and/or data sources, to more comprehensively understand the phenomena of collaborative testing and to provide evidence of validity. ${ }^{11}$ We triangulated our data in multiple ways, including investigator triangulation involving multiple analysts. Not only did we have two analysts analyze the data, a third analyst (BMT) used the categories and themes from the first two analysts to independently code all data, allowing for the verification of all categories and themes. During the coding process, this coder also searched for negative cases that did not fit the categories or themes. We also used triangulation, which involves using different methods to analyze the same phenomena. To ensure this type of triangulation, we collected quantitative data from the Workgroup Emotional Intelligence Profile - Short Version (WEIP-S). ${ }^{12-13}$ The WEIP-S is a 16-item instrument with each item scored from 1 (Strongly Disagree) to 7 (Strongly Agree). The development of the scale, along with validity and reliability evidence can be found in the paper by Jordan and Lawrence. ${ }^{12}$ Our own analysis of the items indicated a Cronbach's alpha of the 16-items as 0.87. Sample WEIP-S items include, "I can read my fellow team members "true" feelings, even if they try to hide them", and "I can talk to other members of the team about the emotions I experience." Students completed the instrument at the beginning of their clerkship following the immediate identification of the members of the established or comparison teams and again during the final week of the clerkship. Mean change scores (post scores - pre scores) were determined for each student in each team. We also collected additional data regarding the team make-up of the established and comparison schools. ${ }^{14}$ We analyzed these data via descriptive and inferential statistics. We set alpha at 0.05. Data were analyzed using IBM SPSS 22.0. We calculated educational 
significance (effect size) using eta squared $\left(\eta^{2}\right)$ and set 0.06 and 0.16 as medium and large-sized effect, respectively, based on published recommendations since there was no prior research to guide us. ${ }^{15}$

\section{Findings}

Focus group data suggested that students experienced a range of emotions while taking the collaborative test. Students in both teams expressed reluctance to take the collaborative test, indicating emotions such as frustration, embarrassment, fatigue or anxiety after recognizing that some of their answers were incorrect. In addition to these generally negative feelings of fatigue and apprehension students also experienced, often to their surprise, some feelings of appreciation and even enjoyment while taking the test. Some students described feelings of camaraderie with their classmates. Others mentioned an appreciation for having the opportunity to learn knowledge and skills while taking the collaborative test, and a number of students even recommended that the collaborative testing experience be extended to other clerkships. Overall, analysis of the focus group data indicated the following themes by students from both teams: 1) The experience was valuable to their learning (i.e., they learned more about psychiatry). 2) Students gained insights into themselves (i.e., they identified ways to improve individual test taking strategies based on observing teammates). 3) They gained insight from others (i.e., increased appreciation for how others think and how the psychiatry clerkship prepared them to take the test). 4) Finally, students gained a greater appreciation for the interpersonal dynamics of teams while taking the collaborative test. (Figure 1) Learning about the Subject Matter 
One of the strongest themes that emerged was that the collaborative test helped students better understand and retain the Psychiatry content. The collaborative test allowed students to discuss the answers and solidify their knowledge. It helped students from established and comparison teams to identify questions they answered correctly and incorrectly and thereby recognize areas of strengths as well as misconceptions or deficits in their knowledge of Psychiatry.

I like it [the collaborative test] because it was the one shelf that I know which question I got right and wrong, 'cause most tests throughout the three years we've done in medical school, I know what my final grade is but I have no clue what information I actually knew or what information I didn't know... I liked that [the collaborative shelf] because now... I know what I don't know in psychiatry and what nuances I missed in studying. (Comparison; Site 5)

\section{Insight into Self}

The collaborative test allowed students from established and comparison teams to gain insight into their test taking ability. It facilitated their understanding of their own strengths and weaknesses during testing.

Ifeel like I learned trends of like how I take [individual]tests, in terms of the questions that were really long, especially towards the end, I got wrong, because I was so tired because I wasn't reading the questions anymore, and it was like a couple ones at the beginning and a couple ones at the end and trying to figure out the answer... ahhh... and so that to me makes me want to work on test endurance... but I learned like little nuances about the way I take tests for myself, which I felt had been really helpful.(Established; Site 3) 
I think it helped you see how you might have misunderstood the reading of the question itself. I think it helps you better learn how you might have misunderstood and missed on the exam. It think that it might reemphasize the questions that you struggle with.(Established; Site 4)

Insight from Others

Collaborative testing helped broaden students' understanding of test taking strategies. By listening to how others interpret test items and what strategies others use to determine the correct answers, they felt they gained insight from others to improve their own critical thinking and problem solving skills for future tests.

I thought it was interesting how other people eliminated certain choices. I think I learned from their test taking skills... seeing how other people approached multiple choice tests. And seeing how sometimes I might actually have come to the test with more knowledge base but they are far better test-takers than me. And seeing how they came to their answers with the same things I knew but I didn't stack things up in the same way they did or I didn't approach the question with the same kind of wording. (Established; Site 2)

"...I didn't go in thinking, "Oh, this is gonna be great." But, then I was surprised as to how much like it was very revelational in hearing about different people's tactics into how they approached these questions. (Established; Site 3)

I think it's helpful to see other people's thought processes whenespecially, when you're trying to defend an answer and if you, you know, you can at least learn about: 'is my thought process correct when I'm tearing apart a question or do we think the same, should I like use some other people's strategy? 
That was interesting when people would explain why they thought what an [answer] is. (Comparison; Site 6)

Interpersonal Dynamics of the Teams

During the collaborative test, students in established and comparison teams described their experiences of negotiating differences, managing strong or overbearing personalities, taking a diplomatic approach, and recognizing when to give in and when to defend an answer.

[I would have liked the] benefit to knowing the group better. I mean, there is a familiarity thing where you don't mind being like embarrassed or those people see you as an intelligent individual, even if you are missing questions they know that you are capable and that kind of confirmed by meeting somebody outside of a straight test situation. (Comparison; Site 5)

... but the fact that like we did have our TBL groups and we knew our groups really well, I loved that like, I was working with my group because I knew them really well, and how we worked. We knew each person [as an] individual, you know, like contribution and how it works, so, I liked that I knew my team. (Established; Site 3)

I think it was better working with a team before we took the shelf because we already knew what dynamic was and who was going to argue a question and who wasn't. So that was like already made up in our minds by the time we got to the shelf it was like, 'Bam Bam Bam Bam let's go. (Established; Site 2) 
...Whenever the two people disagreed, the rest of the group would kind of roll their eyes and look at each other and it was like here we go again. (Established; Site 1)

We were all very worried about hurting someone else's ego. So, we intended to take a lot longer on all of the questions than other groups where, you know, kind of if there was maybe one person who dominated a little bit. So we were very careful to make sure no one's feelings got hurt (laughter) - we voted, we voted again, we voted a third time. So, my group was the last group done and toward the end, the process got a little tedious. (Comparison; Site 6)

\section{Triangulation of Qualitative Results}

Our focus group results suggested benefit for all students, both in established and comparison sites. We searched our data for negative cases, but found none that did not fit our categories and themes. We also triangulated our results with quantitative ratings of team functioning via the WEIP-S change scores pre to post as well as collaborative test results of the teams. A total of 757 students in 137 teams completed both the collaborative test and WEIP-S (response rate 92.54\%), 86 teams from sites with established teams and 51 teams from sites with newly formed comparison teams. Comparison and established teams had approximately 6 members in each team (a mean of 6.1 and 5.9 students, respectively). The gender make-up of the teams was approximately evenly split (51\% and $45 \%$ of team members were male for established and comparison teams, respectively).

Initially the scaled scores were collected for analysis; however, to our surprise, most teams (both established and comparison) scored in the $99^{\text {th }}$ percentile. To increase 
variability in the scores, we rescored the test as raw scores. The two-stage collaborative testing revealed higher scores on the collaborative versus the individual test for both established and comparison teams. While these results were not a surprise for established teams (the same phenomena has been reported in the Team-Based Learning literature), we were surprised that the comparison teams who had not worked together experienced the same gains for team test scores. These results supported our qualitative findings that similar emotions were experienced by students in both comparison and established teams

Data from the WEIP-S allowed us to further triangulate our qualitative findings and further explore potential differences between the two groups. Both groups showed an increase in WEIP-S scores pre (WEIP-S administered at the beginning of the clerkship immediately after team members were identified) and post-(WEIP-S instrument administered during the final week of the clerkship after established teams had worked together for at least 4 sesssions and comparison teams had not worked together). Multivariate analysis of variance indicated that WEIP-S change scores were statistically significantly larger in established versus comparison teams $\left(p<0.01, \eta^{2}=0.86\right)$, with the change scores of 0.25 (CI: 0.20-0.31) and 0.05 (CI: -0.03-0.12) for established and comparison teams, respectively.

All other variables regarding the teams were similar between the two groups (team size, gender composition of the teams, and individual NBME scores of team members). The collaborative test scores (NBME Psychiatry Shelf test raw scores) between the two groups were similar $\left(p=0.35, \eta^{2}=0.35\right)$, with scores of 102.06 (CI: 101.39-102.73) and 101.51 (CI: 100.53-102.49) for established and comparison teams, respectively. 


\section{Insights}

One of the most important findings of our study was that teams, whether established or comparison teams, appeared to benefit from high-stakes collaborative testing. Our results indicated that students in both established and newly formed teams of medical students were able to solidify their content knowledge and learn from their mistakes through a high-stakes collaborative test that was administered in a consistent manner between sites. Individuals in both type of teams reported increased insight into their own test-taking strengths and weaknesses and perhaps more importantly, insight into their critical thinking and problem solving approaches through collaborative interaction with other members, regardless if students were part of established or comparison teams. In vitro studies of mostly low-stakes collaborative testing have indicated that collaborative testing can improve learning by reexposing students to material (reexposure), prompting them to retrieve the information either from memory (retrieval) or through cueing from team members (cross-cueing), and helping students reject misinformation (error pruning). ${ }^{1}$ These mechanisms may have also been at play for our results. Additional studies are needed in this area.

While the WEIP-S (team emotional intelligence) was used for triangulation purposes, the findings from the WEIP-S was interesting in and of itself. Of particular interest was the fact that both the established and newly formed teams showed an increase pre-post. One would expect an increase in the established teams, since the TBL literature has demonstrated that TBL is associated with increases in team emotional intelligence. ${ }^{13}$ The fact that the newly formed teams also demonstrated an increase may be due to non-specific factors (having been on a psychiatry clerkship together, working 
on clinical teams, etc.). Since they had worked together in a TBL setting, it was not suprising that students in the established teams had higher WEIP-S change scores compared to comparison teams. We purport that future research should focus on other potential differences in established versus comparison teams.

In particular, we believe there should be research on how the interpersonal dynamic changes that occur during Tuckman's developmental changes in evolving teams (forming, storming, norming, and performing) ${ }^{16}$ might possibly impact high-stakes collaborative testing. Our qualitative data appeared to suggest differences between established and comparision teams with regards to team interpersonal dynamics. Established teams seem to be at more advanced stages of team development with some functioning well and others clearly at odds (or storming) with each other. We wondered if previous experience within the teams heightened team dynamics. Clearly further exploration of team interpersonal dynamics is necessary to more fully understand highstakes collaborative testing.

Our multisite study provides evidence that high-stakes collaborative testing is feasible for medical students. From a student perspective, emotions associated with high-stakes collaborative testing include fatigue because of the increased time associated with testing and negative emotions that surface when students recognize their mistakes. These two concerns were also identified in one of the few studies of high-stakes collaborative testing in college-level physics education. ${ }^{2}$ Nevertheless, the concerns did not prevent knowledge acquisition previously mentioned. Interestingly, the students we surveyed did not express concerns that others were ill-prepared or had lack of knowledge during the 
collaborative team test, as one might expect. Perhaps higher-stakes collaborative tests foster student preparation.

Our results also suggest that high-stakes collaborative testing is feasible for course directors and administrators. College-level physics education has indicated that it takes little effort to administer two-stage collaborative tests since the collaborative test is usually identical to the individual test. ${ }^{2}$ In addition, it takes little additional time to score consensus collaborative test answers of the teams. While we did not collect data from those who administered the high-stakes collaborative test, the fact that both established and comparison team sites were able to administer the test during each clerkship rotation across an entire year suggests that the collaborative testing is feasible. However, feasibility for course directors and administrators should be studied.

Our study contained a number of limitations. In particular, we only utilized two comparison sites, and these were sites that agreed to participate (not a random sample), which may have limited the generalizability of our results. However, our data suggest that the teams were similar in terms of size and make-up. Additional studies are needed to further validate our findings. In addition, we only gave one two-stage collaborative test, with no follow up to assess long term gains. It would be beneficial to study the longerterm effect of collaborative testing in medical education.

In conclusion, while sufficient evidence exists regarding the benefits of lowstakes collaborative testing in $\mathrm{K}-16$ education as well as the TBL literature in graduate and health science education, limited research has been conducted in high-stakes collaborative testing. Our study points to the potential benefits of high-stakes collaborative testing and provides initial evidence that these benefits can be experienced 
by students in both established and newly formed teams. These data suggest that highstakes tests (tests of learning or summative evaluation) could ALSO become tests for learning or formative evaluation. Our data give rise to additional research questions such as:

- Can other testing modalities beyond multiple choice questions be used effectively during high-stakes collaborative testing?

- What are best practices for maintaining test item security during high-stakes collaborative tests?

- How do the emotions and stress of high-stakes collaborative testing influence student outcomes - both short and longer term?

- What are best practices for ensuring fairness for the collaborative team score?

- How can learners with special needs such as those requiring extended time be accommodated in a high-stakes testing situation?

Given the potential benefits associated with high-stakes collaborative testing, we propose that this is an important area for future study. 
Table 1. Demographic of the 5 different medical schools, including class size, $\%$ state residents attending the school, USMLE step 1 scores, race/ethnicity, and if the site was an established or comparison school site.

\begin{tabular}{|c|c|c|c|c|c|c|c|c|c|c|}
\hline \multirow[b]{2}{*}{ 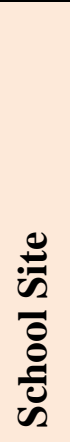 } & \multirow[b]{2}{*}{ 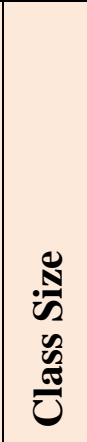 } & \multirow[b]{2}{*}{ 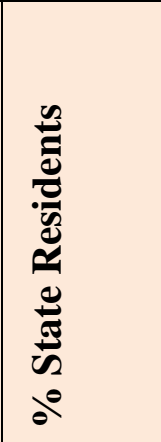 } & \multirow[b]{2}{*}{ 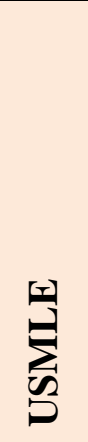 } & \multirow[b]{2}{*}{ 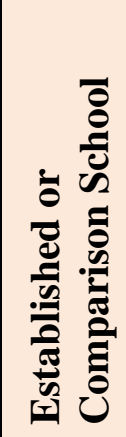 } & \multicolumn{6}{|c|}{ Ethnicity percentages } \\
\hline & & & & & 喜 & 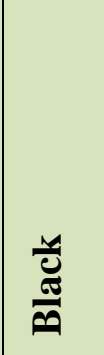 & 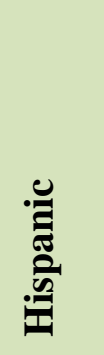 & 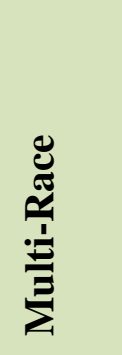 & 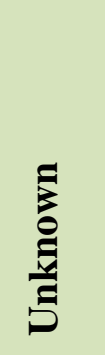 & $\stackrel{\mathscr{E}}{E}$ \\
\hline 1 & 193 & $98 \%$ & 227 & Est & $\begin{array}{l}8.8 \% \\
\text { (17) }\end{array}$ & $\begin{array}{l}10 \% \\
(20)\end{array}$ & $\begin{array}{l}3 \% \\
\text { (6) }\end{array}$ & $\begin{array}{l}2.1 \% \\
\text { (4) }\end{array}$ & $\begin{array}{l}7.3 \% \\
\text { (14) }\end{array}$ & $\begin{array}{l}72.5 \% \\
(140)\end{array}$ \\
\hline 2 & 227 & $93 \%$ & 232 & & $\begin{array}{l}16 \% \\
(32)\end{array}$ & $\begin{array}{l}9 \% \\
(21)\end{array}$ & $\begin{array}{l}17 \% \\
(39)\end{array}$ & $\begin{array}{l}6 \% \\
(15)\end{array}$ & $\begin{array}{l}2 \% \\
(5)\end{array}$ & $\begin{array}{l}48 \% \\
(111)\end{array}$ \\
\hline 3 & 103 & $82.5 \%$ & 224 & Est & $\begin{array}{l}13.6 \% \\
(14)\end{array}$ & $\begin{array}{l}6.8 \% \\
(7)\end{array}$ & $\begin{array}{l}1.9 \% \\
(2)\end{array}$ & $\begin{array}{l}1.9 \% \\
(2)\end{array}$ & $0 \%$ & $\begin{array}{l}75.8 \% \\
(78)\end{array}$ \\
\hline 4 & 165 & $86 \%$ & 223 & Comp & $\begin{array}{l}9.9 \% \\
(16)\end{array}$ & $\begin{array}{l}13 \% \\
(21)\end{array}$ & $\begin{array}{l}2.5 \% \\
\text { (4) }\end{array}$ & $\begin{array}{l}1.24 \% \\
\text { (2) }\end{array}$ & $\begin{array}{l}6.2 \% \\
(10)\end{array}$ & $\begin{array}{l}69.5 \% \\
(112)\end{array}$ \\
\hline 5 & 177 & $\begin{array}{l}\text { NA } \\
\text { (private } \\
\text { school) }\end{array}$ & 226 & Comp & $\begin{array}{l}24 \% \\
(43)\end{array}$ & $\begin{array}{l}12 \% \\
(22)\end{array}$ & $\begin{array}{l}2 \% \\
(4)\end{array}$ & 0 & $\begin{array}{l}11 \% \\
(17)\end{array}$ & $\begin{array}{l}51 \% \\
(91)\end{array}$ \\
\hline
\end{tabular}


Table 2: Interview guide for Students who have taken the High-Stakes Collaborative Test

\begin{tabular}{l|l}
\hline 1. & Effects of the team test on interactions during the course.
\end{tabular}

a. $\quad$ In what ways, if any, did the knowledge that you were going to take a high-stake graded team test influence you interaction with your teammates during the clerkship?

b. How did you feel about the team test - about having a team test influence your grade?

c. Did you or your teammates talk about having to take a team shelf test during the course?

\begin{tabular}{l|l}
\hline 2 & Experience of taking the team test.
\end{tabular}

a. $\quad$ Describe your experience of taking the team test.

b. Were there ever times you felt you had a correct answer on your individual test, but the team decided on a different answer during the team test?

\begin{tabular}{l|l} 
i. & How did that make you feel?
\end{tabular}

c. Compare and contrast team function during your TBL sessions with team function during the NBME team test.

d. How did you feel about taking the individual test and then having to take the team test?

$3 \quad$ Learning during the team test

a.

What, if anything, did you learn during the team test? (Please elaborate)

\begin{tabular}{|l|l|}
\hline i. & About psychiatry? \\
\hline ii. & Yourself? \\
\hline iii. & Your team? \\
\hline
\end{tabular}

b. What, if any, new insights did you have during the team test?

\begin{tabular}{|l|l|}
\hline $\mathbf{i}$ & How did these come about?
\end{tabular}

4. Would you suggest other clerkships adapt team-based team tests? 


\section{Figure 1: Collaborative Testing Themes}

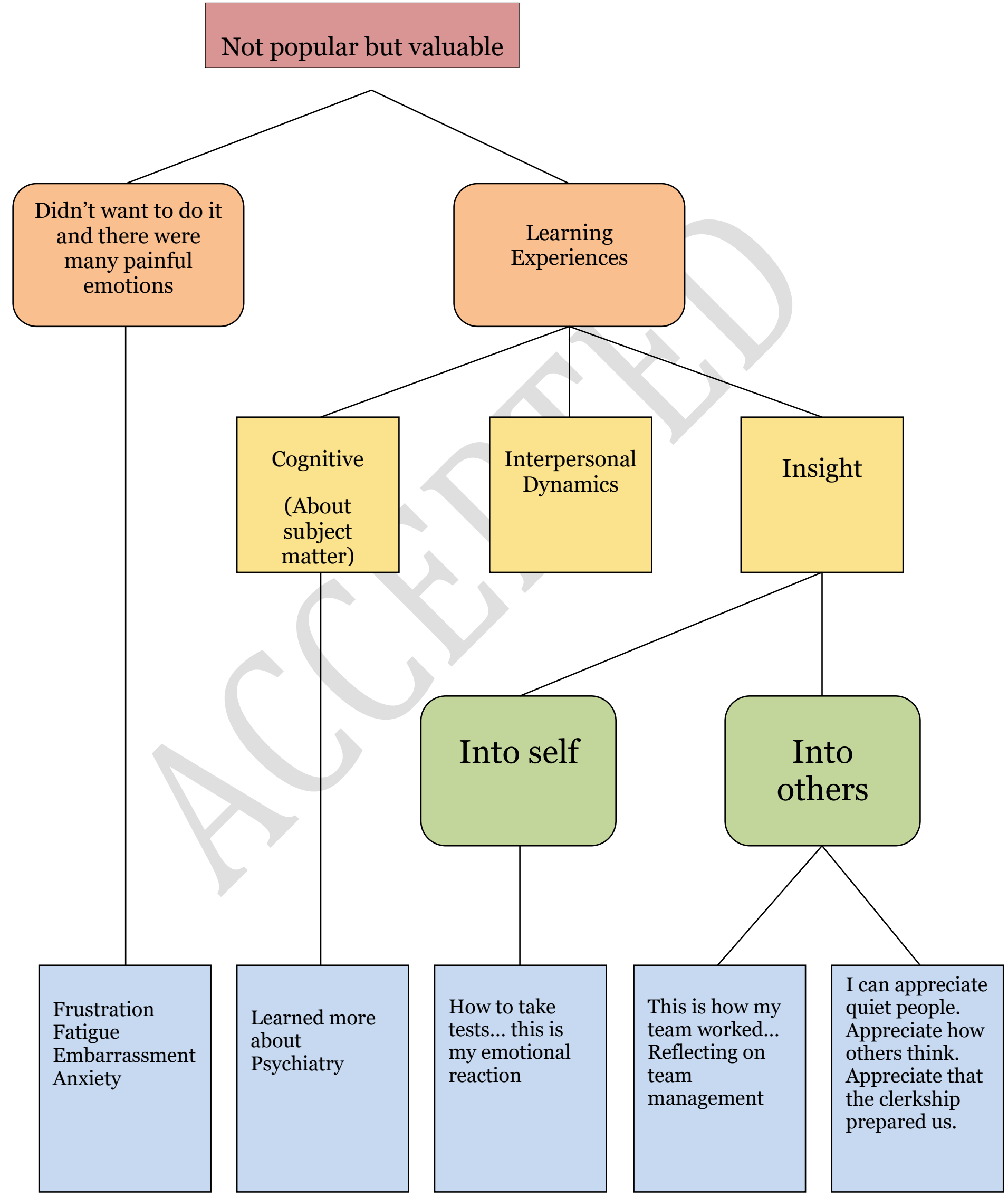




\section{Acknowledgments:}

The authors thank Lindsey Allison, Erina Rivarde, Kenisha Moore, Candice Russell, Melissa Jacob and Shaira Morales for their tireless efforts in managing TBL materials with skill and grace. They also wish to express gratitude for the kindness, generosity, and flexibility of Agata Butler, Dave Swanson and Linette Ross at the National Board of Medical Examiners for allowing use of the subject tests with the student teams and assisting with the scoring and interpretation of NBME data.

\section{Ethical approval:}

This study was approved by the institutional review board of the University of Texas Medical Branch and at each of the other participating schools.

\section{Disclosure statement:}

The authors report no conflicts of interest.

\section{Funding:}

This research was supported in part through a grant from the Association of American Medical College's Southern Group on Educational Affairs and the University of Texas Medical Branch Academy of Master Teachers. 


\section{References}

1. LoGiudice AB, Pachai AA, Kim JA. Testing together: When do students learn more through collaborative tests? Scholarship of Teaching and Learning in Psychology 2015;1:377-89.

2. Rieger GW, Heiner CE. Examinations that support collaborative learning: The students' perspective. Journal of College Science Teaching 2014;4:41-7.

3. Sandahl SS. Collaborative testing as a learning strategy in nursing education. Nurs Educ Perspect 2010;31:142-7.

4. Hanna K, Roberts T, Hurley S. Collaboative testing as NCLEX enrichment. Nurse Educator 2016; 41:171-4

5. Rivaz M, Momennasab M, Shokrollahi P. Effect of collaborative testing on learning and retention of course content in nursing students. Journal of Advances in Medical Education \& Professionalism 2015;3:178-82.

6. Lindsley JE, Morton DA, Pippitt K, Lamb S, Colbert-Getz JM. The two-stage examination: A method to assess individual competence and collaborative problem solving in medical students. Academic Medicine 2016;91:1384-7.

7. Cortright RN, Collins HL, Rodenbaugh DW, DiCarlo SE. Student retention of course content is improved by collaborative-group testing. Advances in Physiology Education $2003 ; 27: 102-8$.

8. Michaelsen LK, Parmelee DX, McMahon KK, Levine RE. Team-based learning for health professions education: A guide to using small groups for improving learning. Sterling, VA: Stylus, 2008. 
9. Michaelsen LK, Sweet M, Parmelee DX. Team-based learning: Small group learning's next big step. San Francisco, CA: Jossey-Bass, 2009.

10. Sweet M, Michaelsen LK. Team-based learning in the social sciences and humanities: Group work that works to generate critical thinking and engagement. Sterling, VA: Stylus, 2012.

11. Merriam SB, Tisdell EJ. Qualitative Research: A guide to design and implementation, $4^{\text {th }} E d$. San Francisco, CA: John Wiley \& Sons, 2015.

12. Jordan PJ, Lawrence SA. Development and initial validation of the Workgroup Emotional Intelligence Profile - Short Version (WEIP-S). Journal of Management \& Organization 2009;15:452-69.

13. Borges, NJ, Thompson BM, Roman B, Townsend M, Carchedi L, Cluver J, et al. Team emotional intelligence, team interactions, and gender in medical students during a psychiatry clerkship. Academci Psychiatry 2015;39:661-3.

14. Thompson, BM, Haidet P, Borges NJ, Carchedi LR, Roman BJB, Townsend MH, et al. Team Cohesiveness, Team Size, and Team Performance in Team-Based Learning Teams. Medical Education 2015;49;4: 379-85.

15. Kline RB. Beyond Significance Testing: Reforming Data Analysis. Methods in Behavioral Research. American Psychological Association: Washington, 2004.

16. Tuckman BW. Developmental sequence in small groups. Psychological Bulletin 1965;63:384-99.

17. Carter N, Bryant-Lukosius D, Dicenso A, Blythe J, Neville AJ. The Use of Triangulation in Qualitative Research. Oncology Nursing Forum 2014;41:545-7. 


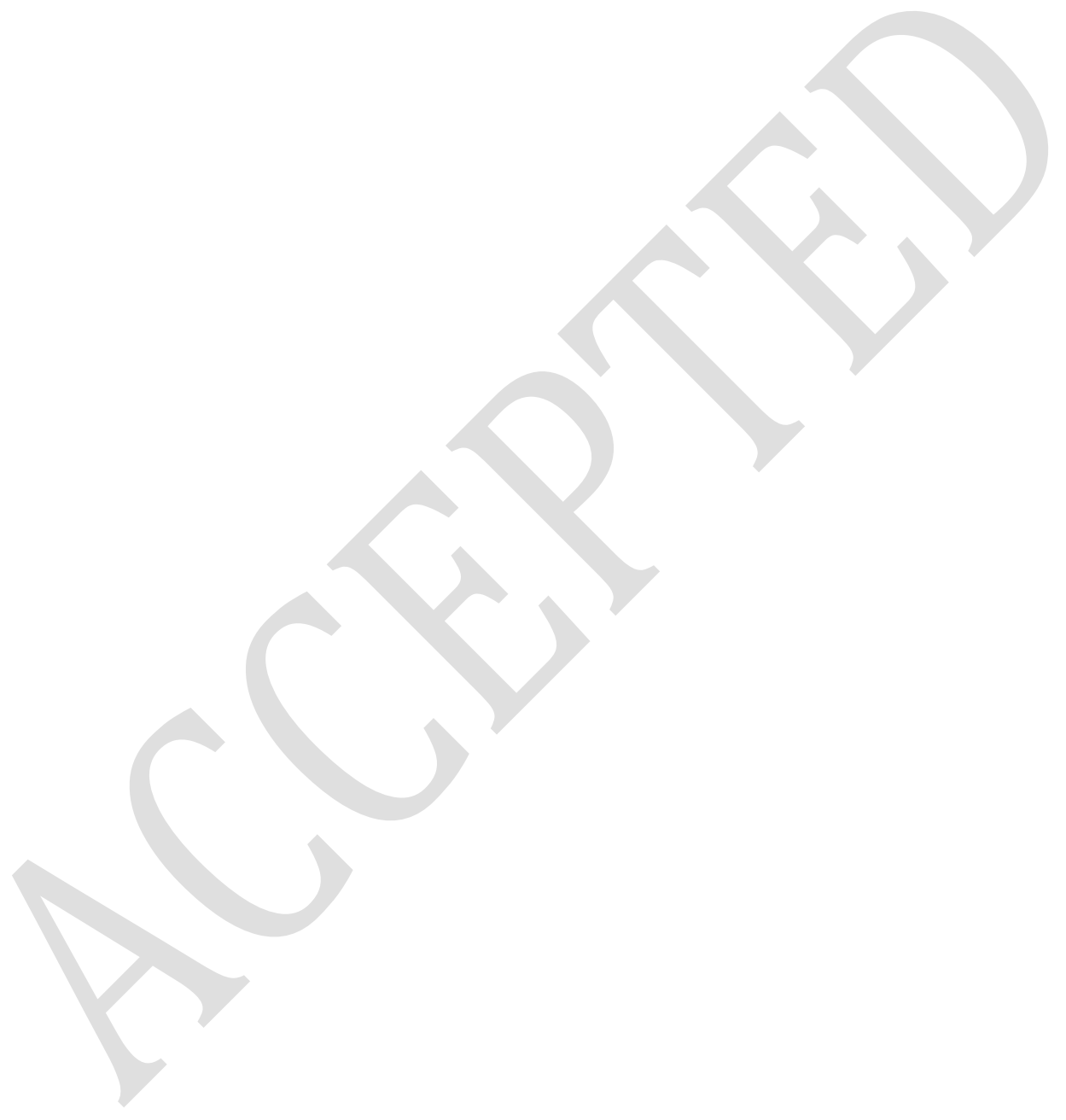

